\title{
Pregnenolone Measurement
}

National Cancer Institute

\section{Source}

National Cancer Institute. Pregnenolone Measurement. NCI Thesaurus. Code C147421.

The determination of the amount of pregnenolone present in a sample. 